\title{
Subjective Assessment of an Innovative Technique for Perineal Colostomy after Abdomino-Perineal Resection for Carcinoma of the Rectum: Towards a Better Quality of Life
}

\author{
MAMDOUH MOUNIR, M.Sc.; MOUNIR ABOUL ELA, M.D.; MOHAMED GAMIL, M.D.; \\ GAMAL AMIRA, M.D.; AHMED FARAG, M.D. and TAREK KHAIRY, M.D. \\ The Department of Surgical Oncology, National Cancer Institute, Cairo University
}

\begin{abstract}
Background: Abdomino-perineal resection is still a procedure of choice in the management of rectal cancer. A left iliac permanent colostomy has a great impact on the quality of life of the patients. Many procedures and techniques have been introduced for the creation of a perineal colostomy aiming at improving the QOL of these patients.

Aim of Study: This work is a scientific practical contribution to improve the quality of life of patients after APR for carcinoma of the rectum. To achieve this, a subjective evaluation of an innovative unprecedented technique for a continent perineal colostomy instead of the left iliac colostomy was done.
\end{abstract}

Material and Methods: A prospective observational study included 20 patients with low rectal cancer treated surgically with APR followed by a perineal colostomy using an innovative technique of a circular smooth muscle cuff. An immediate (Synchronous) reconstruction after APR was done in 14. In 6 patients the operation as a delayed (Metachronous) step 24 years after APR. Patients were subjectively evaluated using Kirwan's scoring system.

Results: Thirteen patients ( $72 \%$ ) were continent; 2 normal continence for gas and stool and 11 patients were continent only for stool. Four patients had minor soiling. Seventeen patients $(94.5 \%)$ were satisfied. Only one patient suffered incontinence.

Conclusion: This new technique proved to be valuable in improving the QOL of patients with rectal cancer after APR. The procedure achieved $94 \%$ patient satisfaction.

Key Words: Rectal cancer - APR - Perineal colostomy QOL.

\section{Introduction}

ADVANCES in surgical procedures and technology have resulted in a decrease in the proportion of patients with rectal cancer undergoing Abdom-

Correspondence to: Dr. Mamdouh Mounir, The Department of Surgical Oncology, National Cancer Institute, Cairo University
ino-Perineal Resection (APR) since its introduction by Miles [1] . APR represents 34\% of surgical procedures for the curative treatment of carcinoma of the rectum in the National Cancer Institute (NCI), Cairo University [2].

From the patient perspective, APR resulting in a permanent stoma impairs Quality of Life (QOL) and has long-term familial, social, psychological and sexual implications in terms of stoma care. This has been addressed in a number of studies [39] . In Egypt, in addition to the aforementioned problems, there is the problem of the regular availability of the stoma appliances and its cost.

APR is still required in selective cases to ensure adequate oncological results and in those patients in whom colo-anal anastomosis is unlikely to give acceptable functional results, such as those with impaired sphincter function, despite the use of techniques such as colo-plasty or a colonic pouch $[10,11]$. APR with permanent left iliac colostomy is usually recommended for low rectal cancer with invasion of the sphincter complex [12]. The range of indications for APR in the treatment of rectal cancer has narrowed as a result of a clear definition of the safe distal resection margin [13], and refinements in surgical technique with the development and application of surgical stapling devices [14] Developed more than 100 years ago, APR remains an important procedure in the treatment of rectal cancer despite advances in sphincter-sparing procedures [15].

Advances in surgical techniques and technology have resulted in a fall in the proportion of patients with rectal cancer undergoing APR to approximately $20 \%[16]$ 
Although cancer-free survivors have escaped the risk of immediate death, still they are not necessarily cancer consequence free. The medical community has now realized that survival cannot be the sole end point of research and clinical practice. For this reason, the WHO and the Food and Drug Administration (FDA) have suggested including QOL data alongside survival and other objective biomedical end points in clinical research [17].

Many procedures and techniques have been proposed for improving the QOL with perineal colostomy implantation; with the use of skeletal muscles (gluteus maximus muscle, gracilis muscle or rectus abdominus muscle), circular smooth muscles cuff from the colon itself and artificial sphincters.

Sato et al., in 1997 [18] published a case report with the modification of gluteoplasty with synchronous pudendal nerve anastomosis. In 2005, they published further data on 19 patients [19]. More recently, Puerta Diaz et al., in 2013 performed delayed gluteoplasty without pudendal nerve anastomosis as a neoshpincter for perineal colostomy patients after APR [20]. Many authors used the graciloplasty as a sphincter for perineal colostomy, with or without electrostimulation [21-24]

The Artificial Bowel Sphincter (ABS) was first described in 1987 by Christiansen \& Lorentzen for the treatment of fecal incontinence [25]. Romano et al., Lirici et al. \& Marchal et al., used ABS as a neosphincter for perineal colostomy after APR in 12 patients with a median age of 59 years (range 46-76). Morbidity ranged from 50-100\%, with evacuation difficulty being a particular problem but also wound infection and erosion of the ABS through the colon wall [26-28].

Schmidt in 1982 described a technique of a continent left iliac colostomy using an autologus colonic sero-muscular graft as a sphincter [29] Lasser and colleagues in 1993 applied Schmidt technique on perineal colostomy under the name of pseudo-continent perineal colostomy; he reported the results of 23 patients [30]. This technique has been applied with satisfactory results on 58 patients at the NCI-Cairo University [31].

Over the past 35 years, this technique, also referred to as Circular Smooth Muscle Cuff (CSMC), has been adopted by many investigators as a perineal colostomy, either immediate or delayed reconstruction after APR.
Federov et al., in 1989 was the first to apply Shmidt technique as a perineal colostomy [32] Lasser has the largest and most famous case series using the name of Pseudo-Continent Perineal Colostomy (PCPC) [33] . A total of 121 patients included in four studies were analysed with respect to continence using different classifications such as the Kirwan-Fazio, Vaizey and modified KellyHolschneider score. Continence was generally stated as "good" or "satisfactory" in 59-71\% of the patients [32-34]. Most of the patients needed retrograde neo-rectal irrigation to facilitate continence.

In Lasser's study, 3 females suffered occasional leaks and needed strict diet despite retrograde colonic enemas. For those 3 patients, Frédéric M et al., implanted an Acticon Neosphincter at a mean of 4.5 years after APR. Leaks and fecal urgency significantly decreased but colonic enemas were maintained. Dietary regulation was less and quality of life improved. All 3 considered the device as a useful adjunct. In this limited experience, implantation of artificial sphincter around a perineal colostomy following APR for rectal cancer appeared feasible and safe even in case of previous radiotherapy. Mid-term tolerance was satisfactory. Continence and quality of life significantly improved [35].

\section{Patients and Methods}

Between February 2015 and February 2017, 117 APRs were performed in the National Cancer Institute, Cairo University. IRB and ethical committee approval was obtained. Perineal colostomy was created in 20 of those patients; 15 men and 5 women with mean age of 36 years.

The idea of the operation was proposed to all patients $(n=25)$ to whom the creation of a permanent left iliac colostomy was hard to accept, provided that they could meet the requirements of this reconstruction and understand its implications. Following clear explanation, three patients finally opted for a definitive left iliac colostomy. One patient proved to be irresectable after exploration. In one patient the procedure was aborted due to extensive adhesions.

All patients presented with low rectal adenocarcinoma, stage II to III disease, they were subject to neo-adjuvant Concomitant Chemo-Radiotherapy (CCRTH) except one patient scheduled for upfront surgery. 


\section{Inclusion criteria:}

- Immediate: Patients with operable, resectable carcinoma of the rectum undergoing AbdominoPerineal Resection.

- Delayed: Patients who underwent AbdominoPerinal Resection with "permanent" left iliac colostomy for carcinoma of the rectum, with at least 2 years disease free survival.

\section{Exclusion criteria:}

- Comorbidities contraindicating major surgery.

- Inoperable tumors either locally advanced or stage IV disease.

- Patients refusing perineal colostomy after detailed informed explanation.

\section{Interventions:}

All patients were subjected to:

- Pre-operative evaluation:

1- Full history and examination.

2- Full laboratory investigations.

3- Appropriate radiological investigations.

4- Colonoscopy and tissue diagnosis.

5- Proper medical and anesthetic assessment.

- Detailed informed consent: A detailed, clear, concise and informed consent is taken. The consent contains: A proposal of the idea, advantages and disadvantages, probable sequelae and complications and patients' education and instructions.

- Operative technique: The study included 2 categories of patients; immediate reconstruction (synchronous with the APR) and delayed reconstruction (metachronous to APR).

\section{1- Immediate reconstruction:}

A- Classic conventional Abdomino-Perinal Resection.

B- Mobilization of the descending colon, splenic flexure and left half of the transverse colon after excision ligation of the upper left colic vessels preserving the marginal artery and the middle colic vessels.

\section{C-Creation of a colonic pedicled flap:}

I- Excision of the appendices epiploecae and peri-colic fat.

II- Laying open the distal $10 \mathrm{~cm}$ at its antimesenteric border.

III- Transection of this distal segment of the mobilized colon short of the marginal artery.

IV- Mucosa is curetted using a scalpel blade.
Thus a pedicled seromuscular flap is created based on the marginal vessels.

D- This pedicled seromuscular flap is wrapped around the distal colon two to four $\mathrm{cm}$ away from its lower edge. It is sutured edge to edge using interrupted vicryl $2 / 0$.

E- Implantation of colostomy in the perineum (Perineal Colostomy):

I- The perineum is closed in 2 layers apart from the site where the stoma is pulled down.

II- The stoma is fixed in females mid-way between the tip of the coccyx posteriorly and the posterior vulval commissure anteriorly. In males, between the tip of the coccyx and the scrotum. It is sutured in place by absorbable sutures.

\section{2- Delayed reconstruction:}

A- Abdominal exploration and meticulous dissection of adhesions.

B- Creating a plane between the presacral fascia posteriorly and the posterior wall of urinary bladder in males or posterior vaginal wall in females anteriorly using sharp dissection.

C- Dissection of the left iliac colostomy from the abdominal wall and classic repair of the stoma site.

D- The same steps from b-e described in the immediate reconstruction are followed.

E- The patient is put in a lithotomy position. An elliptical incision removing the scar of previous APR.

F- Sharp meticulous dissection anterior to the precoccygeal fascia posteriorly and the posterior wall of urinary bladder in males or posterior vaginal wall in females anteriorly.

G- Pulling the distal colon through this created tract.

$\mathrm{H}$ - Implantation of colostomy in the perineum (Perineal Colostomy). It is sutured in place by absorbable sutures.

During the whole procedure, the vascularity and viability of both the pedicle and the stoma is meticulously monitored and assessed.

\section{-Post-operative management:}

1- Routine post-operative care.

2- Starting with the regaining of intestinal motility, daily morning colonic irrigation (enema) using $500 \mathrm{cc}$ of warm saline. 
- On discharge:

Patients were instructed about:

1- Daily colonic irrigation.

2- Regular meals at fixed times.

3- Usage of constipating measures if needed.

4- Follow-up after one month then every 3 months.

Patients were subjectively evaluated regarding continence post-operatively based upon patient satisfaction using the Kirwan classification scoring system regarding continence and patients' satisfaction; including continence to stool and gas, mucous soiling, frequency of defecation as well as dependence on colonic irrigation and need of constipating measures.

\section{Results}

Twenty two patients were explored. The procedure was aborted in 2 of them. One male doomed to have an irresectable tumor in a trial of immediate reconstruction. One female, in a trial of a delayed reconstruction, extensive intestinal adhesions were found which lead to small intestinal injury, repaired and passed a smooth post-operative course.

Twenty patients underwent a perineal colostomy: 15 males ( $75 \%$ ) and 5 females (25\%). Fourteen patients underwent immediate reconstruction $(70 \%)$ and 6 delayed reconstruction (30\%). Two patients underwent delayed reconstruction after 2 years from their APR and 4 patients following 4 years of their initial procedure.

There was no post-operative mortality.

\section{Surgical results:}

Fifteen patients $(75 \%)$ passed a smooth postoperative course. Operative morbidity occurred in 5 patients $(25 \%)$.

Two patients (10\%) had stoma necrosis and complete sloughing of the terminal $10 \mathrm{~cm}$ of the colon as well as the flap during the first week and required reversion of the perineal colostomy into a left iliac colostomy. One developed traumatic multiple fistulous tracts with perineal suppuration due to the use of daily colonic irrigation and improved on systemic and local treatment. One patient developed mild mucosal prolapse without the need of surgical intervention. Thirty months postoperative he developed mucosal polyps, excision biopsy revealed hyperplastic inflammatory nature. One patient from the delayed reconstruction group developed urinary vesico-perineal fistula which appeared after removal of the urinary catheter on day 3 , treated conservatively with a silicon urinary catheter left for 2 weeks. With exclusion of the two cases that had to undergo early reversion to left iliac colostomy, 18 patients were left for evaluation of oncological and functional results.

\section{Oncological results:}

At the end of the study, 18 patients were followed-up with a mean follow-up of 24 months. Although 6 of them underwent APR for their primary disease at an earlier date; follow-up was calculated with the start of the study. All patients presented with low rectal adenocarcinoma, they were subject to neo-adjuvant CCRTH. By the end of the study, 3 patients died from the disease.

\section{Functional results:}

After excluding the 2 patients with sloughed stoma and early reversion into left iliac colostomy, 18 patients were subjectively assessed for functional results.

Patients were assessed 3 months after surgery using the Kirwan scoring system (Tables 1,2) regarding continence and patients' satisfaction.

Table (1): Functional results according to Kirwan scoring system.

\begin{tabular}{llc}
\hline Stage & Description & Number of patients \\
\hline A & Normal continence & 2 \\
B & Gas incontinence & 11 \\
C & Minor soiling & 4 \\
D & Major soiling & 0 \\
E & Incontinence & 1 \\
\hline
\end{tabular}

Table (2): Patients' satisfaction.

\begin{tabular}{llccc}
\hline Stage & No & $\begin{array}{c}\text { Highly } \\
\text { satisfied }\end{array}$ & $\begin{array}{c}\text { Moderately } \\
\text { satisfied }\end{array}$ & Unsatisfied \\
\hline A & 2 & 2 & 0 & 0 \\
B & 11 & 8 & 3 & 0 \\
C & 4 & 3 & 1 & 0 \\
D & 0 & 0 & 0 & 0 \\
E & 1 & 0 & 0 & 1 \\
\hline Total & 18 & 13 & 4 & 1 \\
\hline
\end{tabular}

Assessment after 6 months of 17 patients (one case is excluded due to recurrence) as regards:

- Frequency of defecation: One patient used to evacuate every other day without colonic irrigation. One patient used to evacuate twice daily using colonic irrigation. One patient used to evacuate 4 times per day; well-formed stool without the need of colonic irrigation. The other 14 patients were adapted to evacuate once daily in the morning, 13 patients without irrigation. 
- Colonic irrigation: Four patients did not use colonic irrigation at all. Eleven patients stopped the colonic irrigation within 1 to 3 months. Only 2 patients continued to use colonic irrigation.

- Usage of pads: Apart from the incontinent patient, none needed the use of pads in daytime. Only 2 from the minor soiling group used it per night.

- Use of constipating measures: Four patients used constipating measures for a certain time, but only one continued to use it. It was of no added value with the incontinent patient.

Subjective patient satisfaction was better in the delayed group; gas incontinence and even minor soiling were tolerated.

\section{Discussion}

Many procedures and techniques for perineal colostomy have been devised, abounded, revisited, renovated, modified, innovated and so on. The multiplicity of these procedures certifies that no one of them is ideal and each has its merits.

This study is a prospective observational clinical trial aiming at improving the QOL of patients after APR for carcinoma of the rectum.

This study presents an unprecedented innovative technique in a trial to partially simulate the internal smooth muscle sphincter of the anorectal complex. The technique entangles the creation of a pedicled (CSMC) maintaining its vascular and nervous supply through the integrity of the marginal artery of Drummonds. This study is an innovation of the technique described by Lasser [33].

Shmidt and Lasser confirmed that although it is a graft, it regains its integrity through revascularization and its viability at both histological and functional levels [30-33]. We hereby assume that being a flap and not a graft, the preservation of the integrity of the marginal artery will assure higher level of viability, contractility and tonicity. Maintaining its vascularity, smooth muscles have the advantage of long lasting contractility, tonicity and elasticity over striated muscle flaps. Although it is assumed that the QOL of patients would have been better by avoiding iliac colostomy, 4 patients $(16 \%)$ refused the idea of perineal colostomy. In the study of Lasser, 26 patients out of 66 (39\%) preferred a definitive left iliac colostomy [33]. This difference could be attributed to: The prevalence of younger age population in our study; mean age is 36 years versus 50 in Lasser's study and that lifelong colonic irrigation was an integral part in Lasser's study, which is not the case in ours.
As any CSMC technique, ours is relatively simple compared to dynamic gracilopalsty, gluteoplasty and artificial bowel sphincters. CSMC is done through the same incision, within the vicinity of the field and without neither synthetic materials nor skeletal muscle transposition.

In accordance with different series using different techniques, our procedure proved to be safe where there is neither operative nor post-operative mortality.

The results of this study proved to be comparable to the published data regarding both surgical and functional results.

Reconstructive surgery entangles both surgeryspecific morbidities as well as functional results. Regarding surgical complications, DGP carries 14$74 \%$ early and up to $90 \%$ late complication rates [36] . Puerta Diaz et al., reported 29\% morbidity rate with gluteoplasty [20]. Morbidity ranged from 50-100\% with ABS [26-28].

In our study we reported $25 \%$ complication rate compared to $22-76 \%$ in similar series using CSMC. Apart from the 2 patients (10\%) with stoma necrosis that needed reversion, the remaining 3 $(15 \%)$ were conservatively treated.

It is worth noting that in our study, none of the patients developed stenosis of the neo-sphincter. This could be explained by the aforementioned advantages of the vascularized flap.

Among different methods of subjective assessment of the functional results, we adopted the Kirwan's scoring system for both continence and satisfaction, as it is clear, simply applied and suitable for our patients [37].

Continence was achieved in 13 patients, 2 of them for both gas and stools. Minimal soiling affected 4 patients. Only 1 out of 18 patients suffered incontinence. Normally the 2 patients, continent to gas, were highly satisfied. Out of the 11 patients with class B continence score, $8(\sim 75 \%)$ were highly satisfied and 3 were moderately satisfied; this is referred to their religious background and being anxious to gas incontinence. Out of the 4 patients with minor soiling, 3 (75\%) were highly satisfied and 1 moderately satisfied; this can be explained by that those 3 patients were from the delayed reconstruction group. These patients presented asking for perineal colostomy. In general, the shortcomings of a delayed reconstruction are relatively accepted more than those of an immediate 
reconstruction. This was obviously noted in the incontinent patient who was unsatisfied with the results and still refusing to go back for an iliac colostomy. Although delayed reconstruction is technically and surgically more difficult, it still carries a better outcome regarding patients' satisfaction and QOL. These results are comparable to Lasser's series, who adopted the same scoring system [33].

Anorectal reconstruction techniques are merely addressing sphincter action in the context of continence, without having an optimal replacement for anorectal sensation, evacuation and reservoir capacity.

Difficult evacuation was a common problem observed in almost all the published data, regardless of the technique. The majority of patients ended with the need of lifelong irrigation and/or laxative use to improve evacuation. This was not the case in our study where only 2 patients continued to use colonic irrigation. Four patients did not use colonic irrigation at all, the rest $(\mathrm{n}=11)$ were weaned during a period of 1 to 3 months and none used laxative treatment.

Regarding sensation, 9 of our patients, over time and adaptation to gastro-colic reflex, developed a different kind of sensation in the form of pelvic gurgling prior to the definitive urge of defecation.

Geerdes et al., used DGP and described a form of perception such as periumbilical sensation, hypogastric "murmur" or tension on the transplanted muscle $[38,39]$. Federov used CSMC for reconstruction and reported a considerable number of patients with an urge of defecation and capability of distinguishing between gas and stools [32].

An accurate comparison between different techniques for reconstruction after APR is almost impossible; as all the publications consist of heterogeneous multivariate data. Different scoring systems are used as regarding continence levels, satisfaction and QOL. Violi et al., proposed the idea of a standard scoring system specific for reconstruction procedures after APR [23] .

Most of the published data are case series which do not carry the same level of evidence compared to randomized controlled trials. Although these procedures are practiced by expert surgical teams in highly specialized centers, each is enthusiastic towards the technique he masters.

\section{Conclusion:}

This study presents a novel technique for a neosphincter creation and a continent perineal colostomy after APR for patients with carcinoma of the rectum. It is a scientific practical trial contributing to the effort of improving the quality of life of patients after APR. The procedure achieved $94 \%$ patient satisfaction and $70 \%$ continence with no use of irrigation enemas. At the end, the procedure as a whole proved to be safe, feasible and applicable.

\section{References}

1- MILES W.E.: A method of performing abdominoperineal excision for carcinoma of the rectum and of the terminal portion of the pelvic colon. Lancet, 2: 1812-3, 1908.

2- ELATTAR I.: Annual cancer conference of the Egyptian cancer society. Abstract book, 2015.

3- OLBRISCH M.E.: Development and validation of the ostomy adjustment scale. Rehabil Psychol., 28: 3-12, 1983.

4- NUGENT K.P., DANIELS P., STEWART B., et al.: Quality of life in stoma patients. Dis. Colon. Rectum., 42: 156974, 1999.

5- SILVA M.A., RATNAYAKE G. and DEEN K.I.: Quality of life of stoma patients: Temporary ileostomy versus colostomy. World J. Surg., 27: 421-4, 2003.

6- SCARPA M., BAROLLO M., POLESE L., et al.: Quality of life in patients with an ileostomy. Minerva Chir., 59: 23-9, 2004.

7- ORKIN B.A. and CATALDO P.A.: Intestinal Stomas. The ASCRS Textbook of Colon and Rectal Surgery, 622-42, 2007.

8- ROBERT S.K., LISA J.H., MARCIA G., et al.: HealthRelated Quality of Life among Long-Term Rectal Cancer Survivors with an Ostomy: Manifestations by Sex. Journal of Clinical Oncology, 27: 4664-70, 2009.

9- KONANZ J., HERRLE F., WEISS C., et al.: Quality of life of patients after low anterior, intersphincteric, and abdominoperineal resection for rectal cancer-a matchedpair analysis. Int. J. Colorectal. Dis., 28: 679-88, 2013.

10- MCNAMARA D.A. and PARE R.: Methods and results of sphincter-preserving surgery for rectal cancer. Cancer Control, 10: 212-8, 2003.

11- HERIOT A.G., TEKKIS P.P., CONSTANTINIDES V., et al.: Meta-analysis of colonic reservoirs versus straight coloanal anastomosis after anterior resection. Br. J. Surg., 93: 19-32, 2006.

12-ALLAL A.S.: Sphincter-sparing surgery after pre-operative radiotherapy for low rectal cancers: Feasibility, oncologic results and quality of life outcomes. Br. J. Cancer, 82: 1131-7, 2000.

13- RULLIER E., LAURENT C., BRETAGNOL F., et al. Sphincter-saving resection for all rectal carcinomas: The end of the 2cm distal rule. Ann. Surg., 241: 465-9, 2005. 
14- TYTHERLEIGH M.G. and MORTENSEN N.J.: Options for sphincter preservation in surgery for low rectal cancer. Br. J. Surg., 90: 922-33, 2003.

15- BRIAN W.P. and CHRISTOPHER J.C.: Abdominoperineal Resection: How Is It Done and What Are the Results? Clin. Colon Rectal. Surg., 20: 213-20, 2007.

16- TILNEY H.S., HERIOT A.G., PURKAYASTHA S., et al.: A national perspective on the decline of abdominoperineal resection for rectal cancer. Ann. Surg., 247: 77-84, 2008.

17- VANTZOS E. and ICONOMOU G.: Cancer Survivors. Encyclopedia of Quality of Life and Well-Being Research, 2014.

18- SATO T., KONISHI F. and KANAZAWA K.: Anal sphincter reconstruction with a pudendal nerve anastomosis following abdominoperineal resection: Report of a case. Dis. Colon Rectum., 40: 1497-502, 1997.

19- SATO T., KONISHI F., ENDOH N., et al.: Long-term outcomes of a neo-anus with a pudendal nerve anastomosis contemporaneously reconstructed with an abdominoperineal excision of the rectum. Surgery, 137: 8-15, 2005.

20- PUERTA DIAZ J.D., CASTANO R., LOMBANA L.J., et al.: Use of the gluteus maximus muscle as the neosphincter for restoration of anal function after abdominoperineal resection. Tech. Coloproctol., 17: 425-9, 2013.

21- CAVINA E., SECCIA M., BANTI P., et al.: Anorectal reconstruction after abdominoperineal resection. Experience with double-wrap graciloplasty supported by lowfrequency electrostimulation. Dis. Colon. Rectum., 41: 1010-6, 1998.

22- SANTORO E., TIRELLI C., SCUTARI F., et al.: Continent perineal colostomy by transposition of gracilis muscles. Technical remarks and results in 14 cases. Dis. Colon. Rectum., 37: 73-80, 1994.

23- VIOLI V., RONCORONI L., BOSELLI A.S., et al.: Continent perineal colostomy by electrostimulated graciloplasty in abdominoperineal resection. A preliminary report. Acta Biomed Ateneo Parmense, 67: 131-42, 1996.

24- MANDER B.J., ABERCROMBIE J.F., GEORGE B.D., et al.: The electrically stimulated gracilis neosphincter incorporated as part of total anorectal reconstruction after abdominoperineal excision of the rectum. Ann. Surg., 224: 702-11, 1996.

25- CHRISTIANSEN J. and LORENTZEN M.: Implantation of artificial sphincter for anal incontinence. Lancet, 2: 244-5, 1987.

26- ROMANO G., LA TORRE F., CUTINI G., et al.: Total anorectal reconstruction with the artificial bowel sphincter: Report of eight cases. A quality-of-life assessment. Dis. Colon. Rectum., 46: 730-4, 2003.
27- LIRICI, ISHIDA, Di PAOLA, et al.: Dynamic graciloplasty versus implant of artificial sphincter for continent perineal colostomy after Miles' procedure: Technique and early results. Minim. Invasive Ther. Allied Technol., 13: 34761, 2004.

28- MARCHAL F., LASSER P., LEHUR P.A., et al.: Secondary implantation of an artificial sphincter after abdominoperineal resection and pseudocontinent perineal colostomy for rectal cancer. Gastroenterol Clin. Biol., 29: 425-8, 2005.

29- SCHMIDT: The continent colostomy. World J. Surg., 6: 805-9, 1982.

30- LASSER P., et al.: Pseudo-continent perineal colostomy after amputation of the rectum for cancer. Gastroenterol. Clin. Boil., 17: 181-6, 1993.

31- ABOL ELA M.: Continent perineal colostomy. The annual meeting of Egyptian Society of Surgical Oncology (ESSO), 2009.

32- FEDEROV V.D., ODARYUK T.S., SHELYGIN Y.A., et al.: Method of creation of a smooth-muscle cuff at the site of the perineal colostomy after extirpation of the rectum. Dis. Colon. Rectum., 32: 562-6, 1989.

33- LASSER P., DUBE P., ELIAS D., et al.: Pseudocontinent perineal colostomy following abdominoperineal resection: Technique and findings in 49 patients. Eur. J. Surg. Oncol., 27: 49-53, 2001.

34- GAMAGAMI R.A., CHIOTASSO P. and LAZORTHES F.: Continent perineal colostomy after abdominoperineal resection: Outcome after 63 cases. Dis. Colon. Rectum., 42: 626-30, 1999.

35- FREDERIC M., CAROLE D., LASSER P., et al.: Secondary implantation of an artificial sphincter after abdominoperineal resection and pseudocontinent perineal colostomy for rectal cancer. Gastroentérologie Clinique et Biologique, 29: 425-8, 2005.

36- ROMAN A., DANIEL EBERLI, LUKAS E., et al.: Current aspects and future prospects of total anorectal reconstruction: A critical and comprehensive review of the literature. Int. J. Colorectal. Dis., 30: 293-302, 2015.

37- KIRWAN W.O., TURNBULL R.B., FAZIO V.W., et al.: Pull through operation with delayed anastomosis for rectal cancer. Br. J. Surg., 65: 695-9, 1978.

38- GEERDES B.P., ZOETMULDER F.A. and BAETEN C.G.: Double dynamic graciloplasty and coloperineal pull-through after abdominoperineal resection. Eur. J. Cancer, 31: 1248-52, 1995.

39- GEERDES B.P., ZOETMULDER F.A. and BAETEN C.G.: Total anorectal reconstruction with a double dynamic graciloplasty after abdominoperineal reconstruction for low rectal cancer. Dis. Colon. Rectum., 40: 698-705, 1997. 


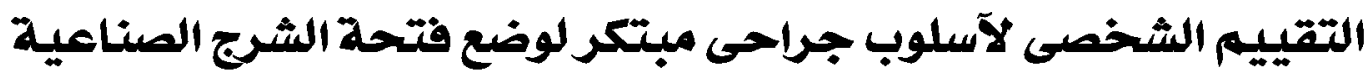

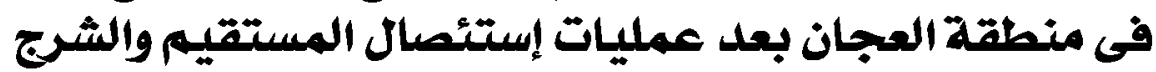

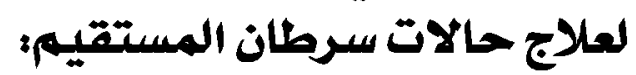 من آجل آسلوب حياة آفضل سلان المشيك}

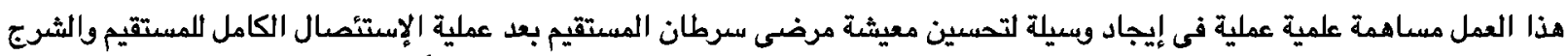

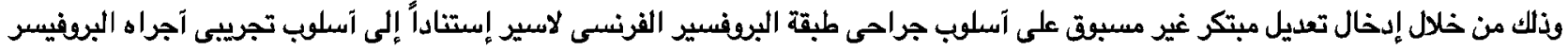

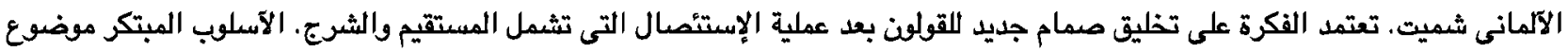

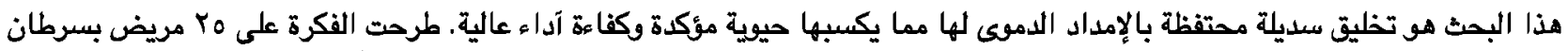

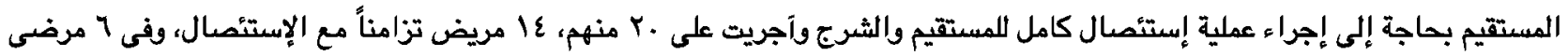

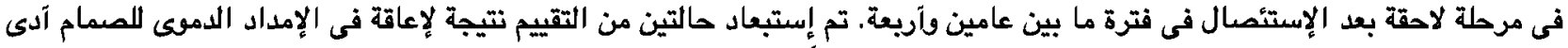
إلى موت الصمام. تم تقييم شخصى اللعملية لعدد ثمانية عشر مريضاً. آسفرت النتائج عن:

• ثلاثة عشر مريضاً يتحكمون فى عملية التبرز، إثنان منهم يتحكمان آيضاً فى إخراج الفازات. • آربعة مرضى عانوا من بلل مخاطى بسيط آمكنهم التكيف والتفاعل معه.

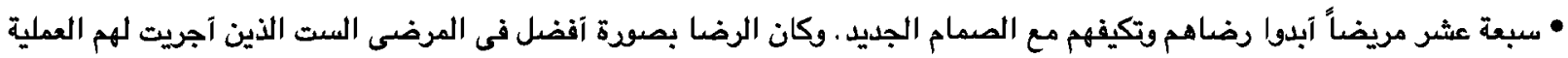
بعد معاناتهم من عملية تحويل البراز. • عشرة مرضى ثبت تدكمه فى عملية إخراج البراز دون الإستعانة بالحقن الشرجية. هذا النسق يشبه نتائج الشخص الطبيعى ولكن بمعدلات آقل.

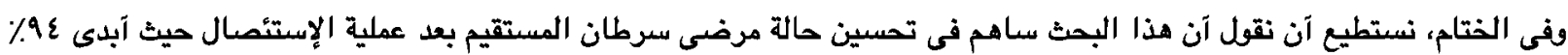
منهم رضاهم الكامل و. ٪\% منهم لم يحتاجوا إلى إستخدام الحقنة الثرجية. نوصى بعرض الفكرة على مرضى سرطان المستقيم الذين يحتاجون إلى الإستئصال الكامل المستقيم والشرج حيث ثبت آنه آمن ويمكن 